\title{
ENTREVISTA COM ÁLVARO FALEIROS
}

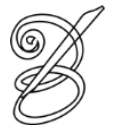 \\ Jakeline Pereira NUNES ${ }^{1}$ \\ Mestranda em Estudos da Tradução (POSTRAD - CAPES) \\ Universidade de Brasília (UnB) \\ Brasília, Distrito Federal, Brasil \\ jakenunes.trad@gmail.com \\ Lorena Torres $\mathrm{TIMO}^{2}$ \\ Mestranda em Estudos da Tradução (POSTRAD - CAPES) \\ Universidade de Brasília (UnB) \\ Brasília, Distrito Federal, Brasil \\ lorenatimo@gmail.com
}

lvaro Silveira Faleiros ${ }^{3}$ nasceu em 1972, em Viña del Mar, Chile. Sua história está
intimamente ligada à ditadura militar no Brasil e aos períodos de exílio de sua
família em diferentes países. Em 1973, com o golpe de Pinochet no Chile, a família
se mudou para a Holanda, por um ano. Após esse período, fixou-se no Canadá, mais especificamente na província do Québec de 1974 a 1979, onde Faleiros teve seu primeiro contato com a língua francesa.

Faleiros é graduado em Ciências Sociais pela Universidade de Campinas (UNICAMP), mestre em Linguística pela Université du Quebec à Montréal (UQAM), Canadá, e doutor em Letras - Língua e Literatura Francesa pela Universidade de São Paulo (USP). É tradutor, pesquisador da área de Tradução e professor livre-docente de Literatura Francesa nessa mesma universidade. Traduz do francês, do espanhol, do finlandês, do japonês, do palikur ${ }^{4} \mathrm{e}$ do kaxinawá 5 .

Esta entrevista foi concedida via videoconferência (FaceTime) a nosso pedido aos alunos da disciplina "Tradução Literária" do Programa de Pós-graduação em Estudos da Tradução (POSTRAD/UnB), ministrada no segundo semestre de 2014 pela Professora Dr. ${ }^{\text {a }}$ Germana Henriques Pereira de Sousa. A disciplina buscava remontar um panorama da prática e da reflexão de uma tradução literária à brasileira. Tal panorama acerca da tradução literária no Brasil está presente na introdução do livro Traduzir o Poema ${ }^{6}$, de Faleiros. Faleiros contou-nos um pouco sobre a sua experiência como tradutor de poesia, refletindo sobre a reimaginação e a retradução de poesia e de outros textos literários para o português do Brasil. 


\section{1) Quais as maiores dificuldades na tradução de poesia para o português do/no Brasil?}

FALEIROS: Hoje, com a lógica de mercado a gente precisa, aliás, precisa não, a gente pode pensar que a tradução de poesia não envolve só a tradução de poesia com o poema, mas envolve todo um contexto de produção dessa obra, obra dessa tradução, dessa reescrita e todas as suas refrações, né? Aquilo está em volta do texto. Então, me parece que a gente teve uma tendência, durante bastante tempo no Brasil, de reduzir as questões de dificuldades de tradução de poesia a uma questão de forma. A dificuldade é a rima, a dificuldade é a métrica, a dificuldade é, na melhor das hipóteses, a metáfora. Uma imagem. Mas eu acho que, hoje em dia, a gente superou essa fase e as questões pelo fato de que o sistema literário está mais consolidado. Construímos uma história em torno da tradução de poesia, as questões mudaram. Hoje as questões se colocam de uma maneira muito mais contextualizada, me parece.

2) Você já fez tradução indireta, de segunda mão? Poderia dar-nos exemplos? Contar uma historinha, um "causo"?

FALEIROS: Já! É... tem alguns livros. Quer ver? Eu vou pegar aqui. Eu vou pegar... Eu vou mostrar para vocês alguns livros [Faleiros se levanta e vai à estante]. Tem essa coleção maravilhosa dos Poetas do Mundo ${ }^{7}$ pela editora da UnB. Esses dois livros eu fiz em parceria com colegas, um é do japonês e o outro é do finlandês. E no caso desses livros, o uso das traduções para o inglês, as traduções para o francês, as traduções para o espanhol desses livros foram fundamentais. Tanto a "Donatela"8 e o "Bezerrinha", que foram meus parceiros nesses trabalhos, falam tanto japonês quanto finlandês, mas o meu trabalho de ajudar na reescrita poética foi todo feito a partir do contato também com leituras que tinham sido feitas nessas outras línguas. Entendeu? E me parece que é o seguinte: é... uma tradução de uma obra, assim, de uma cultura muito diferente, às vezes precisa passar por essas etapas de tradução indireta, de mediação. Temos exemplos interessantes no Brasil, por exemplo, o caso da Cecília Meireles ${ }^{10}$, que traduziu a poesia chinesa. A gente tem vários outros casos: o próprio Galland $^{11}$ que teve um papel muito importante na versão das Mil E Uma Noites no Ocidente. Isso tudo contribui para criar um espaço, um interesse, um primeiro contato e, depois, a partir daí, é abrir o sistema literário para que num médio prazo haja um trabalho mais específico voltado para o mergulho naquelas línguas e culturas. Mas eu acredito que a tradução indireta, quando é feita com o apoio desse aparato crítico, até permite acesso a algumas dimensões da 
obra. Às vezes uma intimidade muito profunda com uma determinada língua não viabiliza acessos por esses mesmos caminhos e, como eu sou um fiel praticante e defensor da retradução, eu acredito que esses projetos vêm se somar. Você vai criando camadas de interpretação de um determinado texto e em um médio prazo você começa a pensar o entendimento daquele texto por meio desses diferentes trabalhos, que se completam.

\section{3) Você consulta outras traduções enquanto traduz?}

FALEIROS: Todas que eu posso. Sempre. Eu agora estou traduzindo As Flores do Mal de Baudelaire. Inclusive agora eu estive em Barcelona e trouxe duas do espanhol e duas do catalão. Eu estou tentando consultar até o Baudelaire em catalão para ver se me ajuda a traduzir para o português.

Thiago Veríssimo" ${ }^{12}$ E essa tradução é por "reimaginação”?

FALEIROS: Olha, a do Baudelaire é. Eu estou tentando trabalhar o ritmo. Eu acho que no caso do Baudelaire, como eu trabalho com a lógica da retradução, me parece que o mais importante no caso dele no Brasil hoje é tentar entender a dimensão prosaica que existe por detrás do seu alexandrino. E, nesse sentido, tanto a leitura do Berardinelli naquele livro $D a$ poesia à prosa ${ }^{13}$, que saiu pela Cosac Naify, quanto a leitura do Erich Auerbach naquele Ensaios de Literatura Ocidental ${ }^{14}$ - que puxa exatamente para essa dimensão prosaica desse verso baudelairiano - e o Auerbach chama atenção para a dimensão do terror, que habita as imagens do Baudelaire e isso acabou ficando em segundo plano nas traduções do Brasil. Então, eu acho que reimaginar Baudelaire nesse sentido é retomar essa imagística e essa sintaxe do Baudelaire hoje. Mas eu acho que não entra naquela brincadeira da reimaginação. Mas não deixa de ter também. Você tem razão, Thiago, no seguinte sentido, é que eu estou tentando fazer uma tradução em que eu não trate mais o verso com a mesma divisão do espaço tradicional, estou colocando os versos uns seguidos dos outros, só separados por uns traços. Justamente para que também na espacialidade essa dimensão prosaica fique explícita. Então, você tem razão sim, eu não tinha pensado nisso, mas, de fato, eu estou reimaginando. 
Thiago Veríssimo: Falando disso, Mário [Faustino] ${ }^{15}$ também faz muito isso, né? Ele fazia as traduções em prosa e marca os versos.

FALEIROS: Mas é justamente isso. Eu estou tentando pensar que o verso sem medida não é necessariamente o verso em prosa, é um verso prosaico. Então, tem um tensionamento na linguagem que é um tensionamento do verso. É diferente do modo, do andamento do texto, da prosa pura. Então, nesse sentido, é uma equação difícil, é uma tentativa verso a verso, poema a poema, que fazem alguns funcionarem melhor e outros não funcionarem tão bem. Então a gente tem que ir ajustando isso e tendo consciência dos limites. É uma tentativa. É mais um capítulo de uma história.

\section{4) Há dificuldades peculiares na tradução de poesia de uma determinada língua?}

FALEIROS: Sim! Eu acredito que sim. Eu acho que, por exemplo, a experiência que eu tive de tentar reinventar o tanka - esse verso junto com o japonês, junto com a Donatela - é de 132 uma ordem completamente distinta. Uma vez eu tive uma conversa interessante com o Paulo Henriques [Britto] ${ }^{16}$ sobre isso. Ele dizia que, às vezes, a proximidade de determinadas línguas é, por um lado, uma facilidade, e por outro lado, uma falsa facilidade, porque ela cria no leitor toda uma expectativa de aderência em relação ao modo de significar daquele texto, que numa língua muito diferente você não tem. Então, quando você lê uma tradução de um soneto de uma língua moderna, ocidental, você tem uma expectativa de reconhecer naquele texto de chegada uma série de modos de significar. Agora se eu digo para vocês que eu estou traduzindo um canto kaxinawá ou um canto araweté, você tem uma expectativa do que é um canto, mas a maneira como aquilo se constrói como linguagem e como espaço retórico de imaginação é o que acaba permitindo ao tradutor um espaço de experimentação muito maior. Uma coisa que eu acho bastante curiosa é que o Mamede ${ }^{17}$ ganha e é indicado todo ano para o prêmio Jabuti pela tradução das Mil e Uma Noites dele, sendo que a maioria das pessoas que julgam esses livros não conhecem nenhuma palavra de árabe. Então, eles estão julgando a partir de uma ideia que eles fizeram do projeto, da dimensão política importante envolvida nisso. Agora a avaliação do texto é feita a partir do texto de chegada. O que também é pertinente, válido, mas o que é curioso é ele ganhar um prêmio de melhor tradução de um texto cuja versão original os avaliadores não conhecem. É interessante para a gente pensar, mas eu acho que isso nos ajuda a entender talvez que a proximidade e a distância em relação 
às línguas, às culturas, a relação aos caminhos retóricos de construção de uma ideia de gênero também vão se modificando e são específicas.

Germana Henriques Pereira ${ }^{18}$ : Álvaro, queria que você falasse um pouquinho sobre a tradução dos cantos kaxinawá, mas não só em termo de dificuldades, mas sobre a questão política dessa tradução, e falasse do lançamento do 'Lance de Dados', que é um evento importante no cenário da tradução, da crítica e da poesia brasileira. Queria que você falasse do último como intervenção numa historiografia da tradução de poesia no Brasil.

FALEIROS: Que ótimo! Vou começar falando do Mallarmé e aproveitar para dizer que esse projeto do Mallarmé nasceu aí na UnB. Foi dando aula de poesia francesa, lendo o poema com os alunos, que eu me dei conta de que a tradução do Haroldo de Campos ${ }^{19}$ realmente inviabilizava o acesso a uma certa narrativa ontológica que está em jogo no poema do Mallarmé. Foi a partir dessa leitura, dessa consciência, que nasceu esse projeto há mais de 10 anos e eu fui trabalhando nele e estabelecendo um diálogo muito importante com o Marcos Siscar, que é um poeta crítico brasileiro que vem pensando a poesia brasileira de um jeito sério, autoral. O Siscar reconheceu nesse desejo de recolocar o Lance de Dados para circular no Brasil a partir de um outro olhar, de um outro entendimento do que está em jogo dentro do poema mesmo. A gente foi estabelecendo um diálogo e inclusive tem um livro dele, Poesia e crise $^{20}$, em que ele tenta recolocar as questões da poesia contemporânea brasileira, usando Mallarmé como um dos pontos de partida para isso. Ele inclusive incluiu o prefácio que está nesse livro no outro que vai ser lançado agora - de poesia e crise. Então, nesse contexto, eu realmente confesso que quando eu me vi com esse livro na mão eu tive uma espécie de vertigem. Um sentimento muito único que eu ainda não tinha sentido nem traduzindo Mallarmé, nem fazendo esses outros trabalhos, porque se trata de um texto muito fundador de um modo de entendimento da poesia no início do século XX. Mas que também teve muita influência no Brasil na segunda metade do século pelo lugar que ocupou dentro do projeto poético dos irmãos Campos, da poesia concreta. Eu acredito que é possível, a partir de agora, com essa tradução como intervenção, recolocar algumas questões, mas sempre nessa lógica de dinamizá-las, historicizando sem achar que se trata de algo melhor ou pior, mas de algo complementar, que está em relação. Eu estou muito contente com esse livro e acredito que realmente foi um trabalho de muito tempo e amadureceu e aconteceu muita coisa no processo. Quando eu já tinha avançado bastante no trabalho, eu descobri uma tradução portuguesa do 
Lance de Dados do Armando Silva Carvalho ${ }^{21}$ e foi muito interessante porque eu já vinha trabalhando há anos nesse livro, daí juntando com aquela pergunta: "você lê as traduções que existem, né"? - Todas as que eu puder sempre. Ler essa tradução foi muito importante porque algumas soluções que eu dava como certas na tradução, muito influenciado pelo Haroldo de Campos, acabei revendo. Revi também algumas coisas interessantes: uma delas, por exemplo, é a palavra "ébat" que em francês significa jogo, brincadeira e que o Haroldo traduziu por "embate". Mas o jogo tem uma dimensão lúdica que o embate não dá conta e ele traduziu aqui, nesse livro, por "folguedo", e eu gostei dessa questão do folguedo, da brincadeira e eu acabei incorporando isso e o poema ficou muito menos bélico. Uma palavra que você mudou, que saiu da sedução da proximidade do som, desse fascínio, desses ecos sonoros, dessas paranomásias (que é tão caro da própria forma que o Haroldo pensa a linguagem) e esse pequeno deslocamento imagético produziu o momento chave - o embate do mestre com o acaso ou jogo do mestre com o acaso. Se ele está se debatendo, ou se ele está jogando, a relação é completamente diferente. Foram três quadros dessas questões que apareceram no contato com essa tradução e eu me lembrei dessa agora. Foi assim, o acaso que não pode ser 134 abolido. Eu estava na Livraria Travessa do Rio de Janeiro e eu cruzei com o livro e abri e “opa, vou levar para casa agora para ler” e o projeto já estava inclusive à primeira prova, já estava com o editor. Isso atrasou o livro em quase um ano porque implicou ver o livro inteiro, mas eu achei que valeu a pena esperar um ano a mais por causa disso.

Germana Henriques Pereira: ah, legal! Inclusive, eu me lembrei que em francês, sobretudo em francês do século XVIII, XIX, eles usam "ébats amoureux”, que são jogos amorosos, é muito longe de "embate" no sentido de confronto. Então, "folguedo" é bem mais feliz, até dentro da relação amorosa.

FALEIROS: É porque era difícil usar a palavra "jogo", porque o "jogo" já aparece muito no poema e aí seria uma espécie de achatamento semântico. Então qual seria a solução? Que brincasse, explorasse a dimensão do jogo, desde que não fosse a palavra jogo. É ligeiro. Bom, mas é isso. Em relação às traduções das poéticas ameríndias, isso é uma questão bastante delicada para mim porque o que acontece no Brasil é que são pouquíssimos os trabalhos que propõem um deslocamento desse universo discursivo para dentro do espaço literário nosso, ocidental. Há dois tipos de projetos que dominam essas poéticas ameríndias: um é o projeto antropológico, que muitas vezes adquire uma dimensão linguística em que são linguistas que 
vão traduzir essas poéticas ou antropólogos, mas poucos deles têm algum tipo de sensibilidade estética para trazer isso para dentro do campo do literário como a gente entende a literatura e, por outro lado, existe uma espécie de folclorização desses discursos. Trata-los, na melhor das hipóteses, como mitos e coisas do folclore da minha gente é um outro tipo de redução complicada. A gente tem a sorte no Brasil de ter uma obra que está sendo redimensionada e tem as leituras e seus valores. Tem a leitura de Gilda de Melo e Sousa ${ }^{22}$ e a leitura de Haroldo de Campos. Tem Macunaíma, de Mário de Andrade, mas existe um trabalho feito recentemente, o Literaturas da Floresta: textos amazônicos e cultura latina americana $^{23}$. É um livro interessantíssimo; ela [Lúcia Sá] é professora de literatura brasileira na Inglaterra e tem um capítulo aqui sobre o Mário de Andrade e sobre o Macunaíma, mostrando que no fundo o Mário se apropriou desse modo de narrar. O modo de construção narrativo é muito mais próximo do modo narrativo de construção com a sua sinapse, com os seus lapsos também cronológicos. A articulação dos encadeamentos das ações, de tudo que está muito mais próximo desse modo de narrar ameríndio, do que a gente poderia supor num primeiro momento e paralelamente a isso tem o trabalho do Antonio Risério ${ }^{24}$, tem o trabalho do Pedro Cesariano ${ }^{25}$, tem também um que é menos articulado, mas muito importante, que é o trabalho do Joseli Viana Batista ${ }^{26}$, do Caca Diegues ${ }^{27}$. Então a gente tem aí um conjunto de pessoas hoje. Também tem o Sérgio Mederios ${ }^{28}$ que foca um conjunto de pessoas que estão recolocando essa questão da possibilidade de oxigenar a literatura brasileira e o próprio imaginário a partir da relação produzida com esses modos de entendimento do mundo e de imaginação. É uma ideia de que eu gosto muito - dos regimes de imaginação. Nesse processo, são traduções indiretas pautadas nos projetos dos antropólogos, mas sem necessariamente lidar com o tipo de rigor metodológico, alcance epistemológico típico da antropologia. Eu acho que a gente pode, desse modo, ir construindo aos poucos uma ideia do que é a literatura brasileira e do que é o fazer, digamos, a poiesis; ampliar o espaço daquilo que poderia ser o poético e a poiesis dentro desse nosso regime de imaginação singular ou dentro da nossa singularidade imaginativa. Eu tenho pensado esse lugar levando em conta um conceito que o Eduardo Viveiros de Castro $^{29}$ usa bastante, é o que ele chama de equívoco controlado ou equivocidade controlada, dependendo. Trata-se de quando você lida com um regime de imaginação muito diferente do nosso ocidental urbano e inevitavelmente nós vamos interpretar determinadas coisas a partir dessa nossa episteme, dessa nossa visão de mundo. Então, quando o índio fala “jiboia”, para ele, “jiboia” é uma entidade, para nós, é uma cobra. Por mais que a gente procure incorporar a entidade que dá vida à jiboia, vamos fazer isso: "ah, 
ele disse que a jiboia, além de jiboia é uma entidade", mas concretamente para ele é uma entidade, para mim é uma ideia de entidade. Então essa distinção é muito importante para ter consciência de que quando você traduz, você controla até certo ponto o equívoco ou a equivocidade, mas o equívoco é constitutivo da relação. No fundo, é nesse espaço do equívoco que você vai ampliando, deslocando, modificando, enriquecendo o teu próprio modo da força de um determinado conceito, um símbolo, uma imagem, uma vivência, uma experiência. Esse processo tem sido muito enriquecedor, é estar disposto a me submeter aos riscos do equívoco e, de vez em quando, controlá-los e perder o controle.

Germana Henriques Pereira: Às vezes um equívoco seu pode dar uma boa leitura lá na frente.

FALEIROS: Isso. Como tem alguns equívocos do Mário de Andrade no Macunaíma que são fundamentais para o desenvolvimento da narrativa que ele fez.

5) Você considera o seu livro "Traduzir o Poema" um manual para a tradução da poesia em 136 trânsito?

FALEIROS: No meu livro, cada capítulo tem uma parte um, dois e três, sobretudo a parte do capítulo dois, quatro e cinco. No dois tem a apresentação genérica de um conceito de semiótica, do espaço gráfico, o metro, a rima, a textura fônica, depois tem umas análises que são as que eu fiz na época do meu doutorado que é o caligrama Voyage [de Apollinaire]. Depois, os versos alexandrinos do francês de octossílabo, a tradução da rima nos caligramas, e Le chant dámour do Apollinaire. Todos estão ligados ao caligrama do Apollinaire. Ao longo dos anos, eu fui me dando conta de que o sistema semiótico era muito interessante como certo ponto de partida, um conhecimento importante da dimensão textual, mas que é por si só. Não se dava conta do fenômeno do poético, da tradução e da relação. Aí eu fui acrescentando em cada um dos capítulos a ideia da reimaginação, a ideia da prosódia, da invenção da rima. Aquele último poema sobre a Hilda Hilst ${ }^{30}$ como uma espécie de ampliação ou de deslocamento das possibilidades dessas ideias eu entendo como um primeiro deslocamento. Para mim, esse livro tem ensinado que você pode partir de determinados conceitos que te ajudem a entender a dimensão textual, mas que o que talvez seja mais vivo dentro desse processo sejam as possibilidades de deslocamento que um determinado conceito pode abarcar ou potencialmente pode ter. A partir dele, você pode ir construindo outras poéticas da relação, 
outros modos de relacionar e de fabricar um projeto de reescrita. Eu tentei mostrar um pouco isso e também foi uma consciência que veio ao longo dos anos de que, no Brasil, engessamos um pouco o entendimento do que seria a tradução do poema. O meu livro, apesar de não ter conclusão, mostra que a poesia não se esgota nesses modelos, o que não quer dizer que eles não sejam válidos como um ponto de partida, mas não necessariamente como o único ou o melhor ponto de chegada. Por isso, a ideia do trânsito é boa sim.

Germana Henriques Pereira: Na disciplina "Tradução Literária", os meninos pediram para fazê-la de forma intensiva e eu concordei desde que a gente fizesse uma "tradução à brasileira". Pegamos John Milton, José Paulo Paes, Paulo Henriques Brito, Boris Schnaiderman e Álvaro Faleiros. Eu tinha lido o começo do livro faz tempo, mas aquela ideia tinha ficado na minha cabeça por conta das conversas que a gente tem e aí quando eu abri de novo eu disse, "mas está aqui a ideia da disciplina". E cada dia era um livro e um autor para cada turno. E foi bem produtivo. Então eu acho que essa conversa deu um fechamento com chave de ouro.

FALEIROS: Eu quero agradecer a vocês a oportunidade também porque, às vezes, a gente tem umas ideias e não tem a oportunidade de explicitá-las. Isso é muito enriquecedor para nos colocarmos nas questões e tentar amadurecer e aprender. E nesse processo todo, uma pessoa que pode vir a contribuir bastante para pensarmos a questão de tradução de poesia no Brasil é a Ana Cristina César ${ }^{31}$, cujo pensamento não teve tempo de amadurecer. Acho que a gente tem que ler os textos dela. Existem algumas chaves que ainda não foram exploradas e que eu acho que podem nos ajudar a já construir um projeto e um próprio entendimento da história da tradução da poesia do Brasil de maneira mais rica. Já ali, ela teve várias intuições que realizou mais ou menos bem, mas, como intuição, eu acho que ela aponta para o que hoje acredito ser o caminho que permite arejar o campo. O Mário Faustino também tem algumas boas.

\footnotetext{
${ }^{1}$ Lattes Jakeline Pereira Nunes. Disponível em: http://lattes.cnpq.br/5271060858486372

${ }^{2}$ Lattes Lorena Torres Timo. Disponível em: http://lattes.cnpq.br/1569763092103244

${ }^{3}$ Lattes Álvaro Silveira Faleiros. Disponível em: //lattes.cnpq.br/0352714063327188

${ }^{4} \mathrm{O}$ palikur é a língua falada pelos palikur (ou palicures), grupo indígena que habita na região do Oiapoque, ocupando o norte do estado do Amapá, no Brasil, e parte da Guiana Francesa.

${ }^{5} \mathrm{O}$ kaxinawá é uma língua indígena falada pelos kaxinawá (ou caxinauás), grupo indígena que ocupa parte do Peru e do estado do Acre, no Brasil.
} 
${ }^{6}$ FALEIROS, Álvaro. Traduzir o Poema. Cotia, SP: Ateliê Editorial, 2012.

${ }^{7}$ Poetas do mundo é uma coleção de livros de poesia traduzidos, em edição bilíngue que conta com introdução do tradutor de cada obra, publicada pela Editora UnB.

${ }^{8}$ Referência desconhecida.

${ }^{9}$ Idem.

${ }^{10}$ Poemas Chineses: Li Po e Tu Fu. [Por: Cecília Meireles]. Rio de Janeiro: Nova Fronteira, 1996.

${ }^{11}$ Antoine Galland (1646-1715) foi um escritor francês e ficou mais reconhecido por ser o primeiro tradutor europeu d'As Mil e Uma Noites.

${ }^{12}$ Thiago André dos Santos Veríssimo atualmente é doutorando no Programa de pós-graduação em Estudos da Tradução (PGET/ UFSC) e colaborou com comentários sobre a tradução poética nesta entrevista, entretanto nem todos os seus comentários foram transcritos. Seu objeto de pesquisa são as traduções realizadas pelo poeta Mauro Faustino, eque teve seu início no mestrado. Sua dissertação de mestrado intitulada "À procura de Mauro Faustino tradutor", defendida na Universidade Federal do Pará, está disponível em: http://repositorio.ufpa.br/jspui/bitstream/2011/5845/1/Dissertacao_ProcuraMarioFaustino.pdf

${ }^{13}$ BERARDINELLI, Afonso. Da poesia à prosa. São Paulo: Cosac Naify, 2007.

14 AUERBACH, Erich. Ensaios de Literatura Ocidental. São Paulo: Editora 34, 2007.

15 Mário Faustino dos Santos e Silva foi jornalista, crítico literário, poeta e tradutor brasileiro. Divulgou a poesia no Jornal do Brasil quando assinava o suplemento dominical do Jornal do Brasil, na seção Poesia-Experiência. É autor de poesia $O$ Homem e sua Hora (1955). Morreu de forma prematura, aos 32 anos, em um desastre aéreo no Peru.

${ }^{16}$ Paulo Henriques Britto é professor universitário (PUC-Rio), poeta e tradutor brasileiro. Já traduziu mais de cem livros, entre obras de William Faulkner, Elizabeth Bishop, Lord Byron e Charles Dickens.

${ }^{17}$ Mamede Mustafa Jarouche é professor de literatura e língua árabe (USP) e traduziu As Mil e Uma Noites.

${ }^{18}$ Germana Henriques Pereira é professora da Universidade de Brasília e pesquisadora da área de Estudos da Tradução. Ministrou a disciplina "Tradução Literária" do Programa de Pós-Graduação em Estudos da Tradução (POSTRAD) $-2^{\circ} / 2014$.

${ }^{19}$ Faleiros se refere à tradução de Haroldo de Campos de Un coup de dés, de Mallarmé, publicada em 1975.

${ }^{20}$ SISCAR, Marcos. Poesia e Crise: ensaios sobre a crise da poesia como topos da humanidade. Campinas, SP: Editora da Unicamp, 2010.

${ }^{21}$ Armando Silva Carvalho (1938) é um poeta e tradutor português.

${ }^{22}$ Gilda de Melo e Souza foi crítica literária, ensaísta e filósofa brasileira. Entre seus livros publicados está: $O$ tupi e o alaúde: uma interpretação de Macunaíma, de 1979. Também é a fundadora da revista Clima.

${ }^{23}$ SÁ, Lúcia. Literaturas da Floresta: textos amazônicos e cultura latina americana. Rio de Janeiro: Editora UERJ, 2012.

${ }^{24}$ Antônio Risério é antropólogo, ensaísta, poeta e historiador. Ele está ligado à pesquisa e promoção da cultura brasileira.

${ }^{25}$ Pedro de Niemeyer Cesariano é doutor em Antropologia Social pela USP. Atualmente, é professor da USP, onde desenvolve pesquisa em sistemas intersemióticos ameríndios e em estudo e tradução em poéticas verbais ameríndias.

${ }^{26}$ Joseli Viana Batista é uma tradutora curitibana. Dedicou-se à tradução literária, experimentando a tradução e a criação de poemas gráficos.

${ }^{27}$ Carlos Diegues é um cineasta brasileiro. Dirigiu, entre outros clássicos do cinema nacional, Orfeu e Deus é brasileiro.

${ }^{28}$ Sérgio Medeiros é poeta, tradutor e ensaísta. Seus trabalhos têm relação com a cultura ameríndia.

${ }^{29}$ Eduardo Viveiros de Castro é antropólogo. Seus livros e ensaios contribuíram significativamente para a antropologia brasileira e a etnologia americanista.

${ }^{30}$ Faleiros faz um comentário sobre a tradução deste poema no quinto capítulo do livro Traduzir o Poema: Hilda Hilst, De la mort. Odes mimimes, Trad. Álvaro Faleiros, São Paulo/ Montreal, Nankin/Norôit, 1997. 
${ }^{31}$ Ana Cristina César ou Ana C. graduou-se em Tradução Literária na Inglaterra, 1962, mas cerca de dez anos antes já atuava como escritora, poetisa e tradutora. Destacam-se, na trajetória como tradutora, a publicação dos poemas de Emily Dickinson em português.

RECEBIDO EM: 02 de dezembro de 2015

ACEITO EM: 07 de dezembro de 2015 